\title{
Downhill skiing following total knee arthroplasty: a survey of Alberta orthopedic surgeons
}

\author{
Andrew Buckley, MD \\ Paul Duffy, MD \\ Robert Korley, MD
}

Accepted Aug. 12, 2020

\author{
Correspondence to: \\ A. Buckley \\ Cumming School of Medicine \\ University of Calgary \\ 3280 Hospital Dr NW \\ Calgary AB T2N 4N1 \\ arbuckle@ucalgary.ca
}

DOI: $10.1503 /$ cjs.009720

\begin{abstract}
Background: In older adults facing knee arthroplasty, the ability to resume downhill skiing postoperatively is unclear. This study aimed to determine the perspectives of Alberta orthopedic surgeons and senior residents regarding downhill skiing after total knee arthroplasty (TKA) or unicompartmental knee arthroplasty (UKA).
\end{abstract}

Methods: In May 2019, a Web-based survey was sent through the Alberta Orthopaedic Society to poll orthopedic surgeons performing arthroplasty and senior orthopedic residents (postgraduate year 4 or 5) in Alberta regarding the permissibility of downhill skiing after TKA or UKA. The survey also elicited information regarding under which conditions or restrictions, if any, surgeons would allow patients to return to downhill skiing, whether these recommendations were evidence based, and whether surgeons had seen complications from downhill skiing in their patients who had undergone knee arthroplasty.

Results: Of the 41 respondents, 21 (51\%) were full-time fellowship-trained orthopedic surgeons, $15(37 \%)$ were specialists with some arthroplasty in their practice, and $5(12 \%)$ were orthopedic residents. Ten of 40 respondents $(25 \%)$ would allow unrestricted downhill skiing after TKA, and $1(2 \%)$ would not allow any skiing at all. The remaining $29(72 \%)$ indicated that they might allow downhill skiing under specific conditions, with the top 3 being limitations on speed and intensity (29 [71\%]), return of full range of motion and strength in the operative knee (26 [63\%]), and years of downhill ski experience (23 [56\%]). Fourteen respondents (34\%) would allow unrestricted downhill skiing after UKA, and $27(66 \%)$ would allow skiing with the same top 3 conditions as for TKA. Thirty-two respondents (78\%) reported that their decisions were not evidence based, and $35(85 \%)$ had never seen complications from downhill skiing after TKA or UKA.

Conclusion: Alberta orthopedic surgeons and senior residents are cautious regarding skiing after knee arthroplasty. The majority reported that their restrictions were not evidence based, which indicates the need for further investigation to develop an approach for surgeons to consistently and safely address return to downhill skiing after TKA or UKA.

Contexte : Chez les adultes âgés qui doivent subir une arthroplastie du genou, la capacité de reprendre la pratique du ski alpin n'a pas été clairement évaluée. Cette étude visait à clarifier le point de vue des chirurgiens et résidents séniors en orthopédie de l'Alberta au sujet de la pratique du ski alpin après une intervention pour prothèse totale du genou (PTG) ou prothèse partielle du genou (PPG).

Méthodes : En mai 2019, un sondage en ligne a été envoyé par l'entremise de l'Alberta Orthopaedic Society afin d'interroger les chirurgiens et résidents séniors (résidents 4 ou 5) en orthopédie pratiquant des arthroplasties en Alberta au sujet de l'autorisation à recommencer le ski alpin après une PTG ou une PPG. Le sondage portait aussi sur les conditions ou les restrictions, le cas échéant, imposées aux patients par leurs chirurgiens pour leur permettre de recommencer à skier, si ces recommandations étaient fondées sur des données probantes, et si les chirurgiens avaient observé des complications chez leurs patients ayant repris le ski après une PTG ou une PPG.

Résultats : Sur les 41 répondants, 21 (51\%) étaient des médecins spécialistes en chirurgie orthopédique à temps complet, $15(37 \%)$ étaient des spécialistes ayant déjà effectué des arthroplasties dans le cadre de leur pratique et 5 (12\%) étaient des résidents en orthopédie. Dix répondants sur 40 (25\%) disaient qu'ils permettraient la pratique du ski alpin sans restrictions après la PTG et 1 (2\%) ne la permettrait pas du tout. Les 29 autres (72\%) ont indiqué qu'ils autoriseraient la pratique du ski alpin à certaines conditions, les 3 principales étant le contrôle de la vitesse et de l'intensité (29 [71\%]), le retour de la pleine amplitude de mouvement et de la force au genou opéré (26 [63\%]) et le nombre d'années d'expérience en ski alpin (23 [56\%]). Quatorze répondants (34\%) permettraient la reprise du ski alpin sans restrictions après la PPG et $27(66 \%)$ l'autoriseraient en appliquant les 3 mêmes conditions que pour la PTG. Trente-deux répondants (78\%) ont indiqué que leur décision ne reposait pas sur des données probantes et 35 (85\%) n'avaient observé aucune complication après la reprise de la pratique du skin suite à une PTG ou une PPG.

Conclusion : Les chirurgiens et les résidents séniors en orthopédie de l'Alberta émettent des réserves relativement à la reprise de la pratique du skin après une arthroplastie du genou. Chez la majorité, les restrictions préconisées ne reposent pas sur des données probantes, ce qui indique que la recherche à ce sujet mérite d'être approfondie afin qu'on puisse élaborer une approche cohérente et sécuritaire en orthopédie pour la reprise de la pratique du ski alpin après une PTG ou une PPG. 


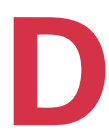
ownhill skiing is a common and popular sport among people of all ages in Alberta. It is often one of the last high-impact sports that people pursue as they age. The ability to continue to perform high-impact sports such as downhill skiing postoperatively can be a major preoperative concern for people facing the need for knee arthroplasty. This is complicated by rising patient expectations of the postoperative function of the implant. ${ }^{1}$ Opinions in the literature concerning participation in sports after knee arthroplasty are varied. ${ }^{1-3}$

In general, the rate of performing sports activities has been found to decrease after total knee arthroplasty (TKA). Huch and colleagues ${ }^{4}$ reported that the sport activity rate at 5 years postoperatively was $34 \%$, compared to $42 \%$ preoperatively. A similar study showed that 43 (77\%) of 56 patients who were active and exercising before TKA were able to resume their sporting activity a mean of 5 years postoperatively. ${ }^{5}$ Reported rates of return to sports after unicompartmental knee arthroplasty (UKA) are higher. Fisher and colleagues ${ }^{6}$ found that more than $90 \%$ of patients improved or maintained their recreational sporting activity a mean of 18 months after unicompartmental surgery. In a retrospective evaluation, Williams and colleagues $^{7}$ used the UCLA activity rating scale to determine which variables could predict return to sports activities after TKA or UKA and found 4 factors that best predicted return to intense activity: younger age, lower body mass index, male sex and higher preoperative UCLA activity rating scale scores. In a similar study, Wylde and colleagues ${ }^{1}$ found that, in the 3 years leading up to TKA or UKA, $29.9 \%$ of patients remained active in some capacity of sport. The most predictive factor of remaining active before joint replacement was age, with younger patients typically maintaining activity more commonly. Almost three-quarters $(73.4 \%)$ of patients in this active group were able to participate in some capacity in sports activities postoperatively. The largest decline in activity was among patients who had participated in high-impact sports. Among patients who discontinued sporting activity after TKA or UKA, the most common reasons for discontinuation were pain in the operative joint, inability to perform required movements and medical advice.

There is agreement about patients' performing lowimpact activities such as walking, cycling and swimming after TKA or UKA., ${ }^{1,2}$ However, few studies have investigated the effects of higher-impact activities like skiing on the longevity of an artificial knee. ${ }^{8-10}$

Although there are studies in the literature regarding the physiologic impact to implants from sports participation after arthroplasty, ${ }^{11,12}$ surgeons' perspectives on return to specific sports are less well known. McGrory and colleagues ${ }^{3}$ found that orthopedic surgeons, fellows and residents would recommend (based on 75\% consensus) lowimpact sports such as swimming, golfing, bowling and cycling after knee replacement, but not higher-impact sports such as running, racquetball, basketball or football because of the perceived increased risk to the artificial joint. It is also unclear under which conditions, if any, surgeons would allow their patients to return to skiing after TKA or UKA.

Total knee replacement is a common surgical intervention in Alberta: in 2018, surgeons in the province performed 3287 total or bilateral knee replacement procedures. ${ }^{13}$ The primary aim of the current study was to identify whether Alberta orthopedic surgeons and senior residents would allow patients to return to downhill skiing after TKA or UKA. Our secondary aims were to determine 1) under which conditions or restrictions, if any, surgeons would allow patients to return to downhill skiing, 2) whether these recommendations were evidence based and 3) whether surgeons had seen complications from downhill skiing in their patients who had undergone knee arthroplasty.

\section{Methods}

\section{Participants}

Orthopedic surgeons living in Alberta who performed knee arthroplasty surgery were identified through the Alberta Orthopaedic Society. Senior orthopedic residents (postgraduate year 4 or 5) were identified through their respective programs at the University of Alberta and the University of Calgary. All identified surgeons and residents were contacted via email in May 2019 with an invitation to participate in a Web-based survey regarding skiing after TKA or UKA. A follow-up email was sent 3 months later to include any potential participants who did not participate in the first survey.

As this survey was considered a quality-assurance project, and no patients were contacted, research ethics board approval was not needed.

\section{Survey}

The survey elicited information about practice setting (academic university-affiliated hospital v. community hospital), personal practice pattern (full-time fellowshiptrained arthroplasty surgeon, specialist with some arthroplasty in practice, or senior resident in orthopedics) and number of years in practice. This was followed by questions regarding the permissibility of downhill skiing after TKA or UKA, conditions or limitations to downhill skiing, whether recommendations were evidence based and whether respondents had seen complications from downhill skiing in their patients who had undergone arthroplasty (Appendix 1, available at canjsurg.ca/009720-a1).

\section{Statistical analysis}

We report simple average values. 


\section{RESULts}

Forty-one orthopedic surgeons and residents completed the survey. The majority of respondents (24/40 [60\%] practised in academic university-affiliated hospitals (Table 1). Of the 41 respondents, 21 (51\%) were full-time fellowship-trained arthroplasty surgeons, 15 (37\%) were specialists with some arthroplasty in their practice, and 5 (12\%) were orthopedic residents. Almost half (17 [47\%]) of the 36 surgeons and specialists had been in practice for 16 years or more.

Of the 40 respondents who answered the question about limitations, 1 (2\%) would completely prohibit patients from downhill skiing after TKA, and 10 (25\%) stated that they would advise patients that unrestricted downhill skiing would be allowable after TKA. The remaining 29 respondents (72\%) stated that they might allow downhill skiing, but with specific conditions or limitations, with the top 3 being limitations on skiing speed and intensity (29 [71\%]), return of range of motion and strength of the operative knee (26 [63\%]), and a certain number of years of downhill ski experience (23 [56\%]) (Table 2). Two respondents (5\%) had no limitations. Twenty-nine respondents (71\%) said their recommendations would not change in the case of a patient who had undergone bilateral TKA, and $11(27 \%)$ stated that they would place more limitations on skiing if a patient had undergone bilateral TKA.

None of the 41 respondents indicated that they would fully prohibit downhill skiing after UKA, and 14 (34\%) reported no restrictions. Twenty-seven respondents (66\%) would place certain conditions or restrictions, with the 3 most common being the same as for TKA: limitations on speed and intensity (23 [56\%]), return of range of motion and strength of the operative knee $(23[56 \%])$ and years of downhill ski experience (19 [46\%]).

Respondents indicated the following reasons for not allowing downhill skiing after TKA or UKA: fear of periprosthetic fracture, fear of other complications, no literature to support skiing after TKA or UKA, and fear of early implant loosening.

The majority of respondents (32 [78\%]) indicated that their recommendations were not evidence based.

Six respondents $(15 \%)$ reported that they had seen complications due to downhill skiing in patients in their practice who had undergone TKA or UKA.

\section{Discussion}

In general, Alberta orthopedic surgeons and senior residents in orthopedics appear to approach downhill skiing after TKA and UKA cautiously. The majority reported being willing to allow patients to continue skiing, but with certain conditions or limitations. The most common restrictions and limitations reported by our respondents
Table 1. Practice setting, personal practice pattern and years in practice of Alberta orthopedic surgeons and senior orthopedic residents

\begin{tabular}{|lc|}
\hline Characteristic & $\begin{array}{c}\text { No. (\%) of } \\
\text { respondents } \\
n=41\end{array}$ \\
\hline Practice setting & $24(59)$ \\
\hline Academic university-affiliated hospital & $16(39)$ \\
\hline Community hospital & $1(2)$ \\
\hline Not reported & $21(51)$ \\
\hline Personal practice pattern & $15(37)$ \\
\hline Full-time fellowship-trained arthroplasty surgeon & $5(12)$ \\
\hline Specialist with some arthroplasty in practice & $6(17)$ \\
\hline Resident in orthopedics & $6(17)$ \\
\hline Years in practice for surgeons/specialists $(n=36)$ & $7(19)$ \\
\hline$\leq 5$ & $17(47)$ \\
\hline $6-10$ & \\
\hline $11-15$ & \\
\hline$\geq 16$ &
\end{tabular}

Table 2. Conditions or limitations under which respondents would allow patients to return to skifing after total knee arthroplasty

\begin{tabular}{|lc|}
\hline Condition/limitation* & $\begin{array}{c}\text { No. (\%) of } \\
\text { respondents }\end{array}$ \\
\hline Limitations on speed and intensity & $29(71)$ \\
\hline $\begin{array}{l}\text { Return of range of motion and strength in operative } \\
\text { knee }\end{array}$ & 26 (63) \\
\hline Years of downhill ski experience & 23 (56) \\
\hline After 6 mo of rehabilitation & $13(32)$ \\
\hline \begin{tabular}{l} 
Physiologic age of patient \\
\hline Type of total knee arthroplasty
\end{tabular} & 9 (22) \\
\hline \begin{tabular}{l} 
Only cross-country skiing \\
\hline Only with use of soft or rigid knee brace
\end{tabular} & 2 (5) \\
\hline $\begin{array}{l}\text { Othert } \\
\text { *Respondents could select more than 1 condition or limitation. } \\
\text { tIncludes full rehabilitation of quadriceps; graduated return; proper warm-up; no deep } \\
\text { powder, major moguls or steep terrain; and patient's full understanding that artificial } \\
\text { knees are meant for walking, not skiing. }\end{array}$ \\
\hline
\end{tabular}

(speed and intensity of skiing, return of range of motion and strength in the operative knee, and number of years of skiing experience) suggest that surgeons want to avoid injury of the artificial knee. Only 1 respondent indicated a complete prohibition of downhill skiing after TKA. Respondents were somewhat more permissive on allowing unrestricted skiing after UKA.

The most frequent condition in order to downhill ski after both TKA and UKA was a limitation on speed and intensity, which indicates a perceived threat to implant integrity based on the aggressiveness of the activity. This is an understandable concern for surgeons, given that TKA and UKA have well-recognized limitations in terms of longevity and revisions. ${ }^{2,45}$ However, there are few reports of skiing-related implant complications after several years of follow-up. ${ }^{8-10}$ Mont and colleagues ${ }^{8}$ found that, among patients participating in high-impact activities including 
skiing, of 33 replaced knees, only 1 needed revision after 4 years. Those authors concluded that, although they did not recommend high-impact sports after TKA, the numbers showed they could be performed safely in terms of risk for revision within 4 years of operation. Bercovy ${ }^{9}$ reported that no aseptic implant loosening was observed after a mean follow-up interval of 7.5 years in 30 patients who participated in downhill skiing after TKA. This suggests that some degree of intense activity is possible after knee replacement.

It is reasonable to assume that a skier's years of experience would correlate with objective skill level and that more skilled skiers would have lower potential for injury. Combining experience and rehabilitation, Würth and colleagues ${ }^{14}$ used downhill skiing as a supervised part of TKA rehabilitation in experienced skiers. They found that skiing enhanced patients' postoperative psychologic well-being, and had no impact on their perceived pain or function in the operative knee. In a branch of the same study, 16 patients who had undergone TKA were examined a mean of 2.3 (standard deviation 0.1) years after skiing about 80 days over 3 seasons, including a ski intervention 2-3 times per week for 12 weeks. ${ }^{10}$ All 16 had excellent clinical and radiologic outcomes, and no implant loosening or additional polyethylene wear was noted.

In a recent survey by the American Association for Hip and Knee Surgeons, surgeons were asked about several high-impact sports including skiing. ${ }^{2}$ Skiing was separated into groomed terrain and difficult terrain. For groomed terrain, $43.8 \%$ of surgeons allowed unlimited skiing, 39.6\% occasional skiing (1-2 times per month), and $16.1 \%$ no skiing. There was a positive correlation $(p=0.003)$ between surgeon volume of TKA procedures and allowing unlimited skiing on groomed terrain. There was significantly more agreement regarding skiing on difficult terrain, with only $3.7 \%$ allowing unlimited skiing, $10.1 \%$ allowing occasional skiing, and $85.9 \%$ discouraging the activity completely. As in the current study, respondents reported that they did not base these decisions on scientific evidence.

Fifteen percent of our respondents indicated that they had seen a complication from downhill skiing in patients in their practice who had undergone TKA or UKA. This rate seems high compared to reported rates of skiing-related implant injuries. ${ }^{3,9,10,14}$ It is possible that the cases observed by our respondents represent a small fraction of cases belonging to physicians who had been in practice longer or perhaps had a combined trauma and arthroplasty practice. The numbers suggest that such complications are infrequent, yet when they do occur they are obviously severe enough to cause a substantial amount of caution among surgeons.

Almost 4 of 5 respondents reported that their recommendations were not evidence based. Protection of the implant after TKA or UKA is a top priority for surgeons, and, as such, placing certain limitations appears to be the predominant "safe bet." This speaks to the need for further investigations of the safety and dangers of carefully monitored downhill skiing after knee arthroplasty.

\section{Limitations}

An inherent limitation of the study design is an inability to distinguish whether the views of the respondents differed from those of the nonrespondents, which may have introduced a sampling or selection bias. We took into account only the frequency with which a limitation was chosen, and were unable to measure the relative strength of any particular surgeon recommendation. Participation of 41 surgeons and residents (about half of orthopedic surgeons and senior residents in Alberta) represents a strength of this survey, given the known limitations of Web-based surveys. ${ }^{15}$

\section{Conclusion}

A substantial proportion of responding Alberta orthopedic surgeons and senior residents reported thinking that downhill skiing after knee arthroplasty is safe provided certain restrictions, such as limitation of the speed and intensity of skiing, return of range of motion and strength in the operative knee, and skiing experience, are in place. These restrictions were not evidence based. Further investigation in the form of a prospective trial is needed to develop an approach for surgeons to consistently and safely address return to downhill skiing after TKA or UKA. It is also necessary to assess the long-term implications of downhill skiing on implant longevity and complications.

Affiliation: From the Cumming School of Medicine, University of Calgary, Calgary, Alta.

Competing interests: None declared.

Contributors: All authors designed the study, acquired and analyzed the data, wrote and critically reviewed the article, and approved the article for publication.

Content licence: This is an Open Access article distributed in accordance with the terms of the Creative Commons Attribution (CC BYNC-ND 4.0) licence, which permits use, distribution and reproduction in any medium, provided that the original publication is properly cited, the use is noncommercial (i.e., research or educational use), and no modifications or adaptations are made. See: https://creativecommons. org/licenses/by-nc-nd/4.0/.

\section{References}

1. Wylde V, Blom A, Dieppe P, et al. Return to sport after joint replacement. F Bone foint Surg Br 2008;90-B:920-3.

2. Swanson EA, Schmalzried TP, Dorey FJ. Activity recommendations after total hip and knee arthroplasty: a survey of the American Association for Hip and Knee Surgeons. 7 Arthroplasty 2009;24:120-6.

3. McGrory BJ, Stuart MJ, Sim FH. Participation in sports after hip and knee arthroplasty: review of literature and survey of surgeon preferences. Mayo Clin Proc 1995;70:342-8.

4. Huch K, Müller KAC, Stürmer T, et al. Sports activities 5 years after total knee or hip arthroplasty: the Ulm Osteoarthritis Study. Ann Rheum Dis 2005;64:1715-20. 
5. Bradbury N, Borton D, Spoo G, et al. Participation in sports after total knee replacement. Am 7 Sports Med 1998;26:530-5.

6. Fisher N, Agarwal M, Reuben SF, et al. Sporting and physical activity following Oxford medial unicompartmental knee arthroplasty. Knee 2006;13:296-300.

7. Williams DH, Greidanus NV, Masri BA, et al. Predictors of participation in sports after hip and knee arthroplasty. Clin Orthop Relat Res 2012;470:555-61.

8. Mont MA, Marker DR, Seyler TM, et al. High impact sports after total knee arthroplasty. 7 Arthroplasty 2008;23:80-4.

9. Bercovy M. Sports after total knee replacement: Are intense contact sports possible? Artbroscopy 2017;33:e116-7.

10. Hofstaedter T, Fink C, Dorn U, et al. Alpine Skiing With total knee ArthroPlasty (ASWAP): clinical and radiographic outcomes. Scand $\mathcal{F}$ Med Sci Sports 2015;25(Suppl 2):10-5.
11. Amstutz H, Le Duff MJ. Effects of physical activity on long-term survivorship after metal-on-metal hip resurfacing arthroplasty. Bone foint 7 2019;101-B:1186-91.

12. Lavernia CJ, Sierra RJ, Hungerford DS, et al. Activity level and wear in total knee arthroplasty: a study of autopsy retrieved specimens. $\mathcal{F}$ Arthroplasty 2001;16:446-53.

13. Wait times for hip and knee replacement. Calgary: Alberta Bone and Joint Health Institute; 2019. Available: www.albertaboneandjoint. com/for-patient/wait-times/ (accessed 2019 Mar. 19).

14. Würth S, Finkenzeller T, Pötzelsberger B, et al. Alpine Skiing With total knee ArthroPlasty (ASWAP): physical activity, knee function, pain, exertion, and well-being. Scand J Med Sci Sports 2015;25(Suppl 2):74-81.

15. Grava-Gubins I, Scott S. Effects of various methodologic strategies: survey response rates among Canadian physicians and physicians-intraining. Can Fam Physician 2008;54:1424-30. 